\title{
Erro médico no estado de Rondônia: uma realidade nacional
}

\author{
Medical error in the state of Rondônia: A national reality \\ Error médico em el estado de Rondônia: Una realidad nacional
}

Daniel Carlos Neto*1

\begin{abstract}
RESUMO
Objetivo: Colaborar para a amplificação da compreensão da realidade em busca de segurança jurídica no exercício da medicina. Método: Estudo descritivo, de análise transversal quali-quantitativo, baseado na avaliação retrospectiva dos Acórdãos dos Recursos de Apelação, através de pesquisa de jurisprudência disponível do Tribunal de Justiça do Estado de Rondônia (TJRO) no período compreendido entre 01/01/2015 a 31/04/2018. Resultado: Foram analisados 58 julgados, tendo como principal especialidade em ordem decrescente a Obstetrícia, Ginecologia e Cirurgia Geral. A principal causa petendi foi a Negligência (58,6\%). Constatou-se que nas causas em que tiveram Perícia Médica $68 \%$ foram julgadas improcedentes e nas que não tiveram 51,1\% foram procedentes. Conclusão: Após análise, constataram-se diversos fatores que ocorrem concomitantes à gênese do erro médico, sobretudo a relação médico-paciente, as péssimas condições de trabalho, o sucateamento da saúde no Brasil, a má qualidade do ensino médico, entre outros, frente à vulnerabilidade de conhecimento jurídico, como forma de alcançar mecanismos que lhes permita delinear estratégias que minimizem os riscos potenciais de fenômenos jurídicos desfavoráveis no exercício da atividade médica. Por fim, quanto aos meios de prova, constata-se que a perícia médica assume importância extrema e indispensável, para ampla defesa do médico.
\end{abstract}

Palavras-chave: Erro Médico, Ética médica, Imperícia, Imprudência, Negligência, Perícia Médica, Responsabilidade civil.

\begin{abstract}
Objective: Collaborate to amplify the understanding of reality in search of legal security in the practice of medicine. Method: A descriptive cross-sectional qualitative study, based on the retrospective evaluation of Appellate Appeals Judgments, through a study of the available jurisprudence of the Court of Justice of the State of Rondônia (TJRO) in the period from 01/01/2015 to 04/31/2018. Results: Fifty-eight judged were analyzed, having as main specialty in descending order the Obstetrics, Gynecology and General Surgery. The main petendi cause was Neglect (58.6\%). He found that in the cases in which they had Medical Expertise $68 \%$ were judged Overdue and in those who did not have $51.1 \%$ were coming. Conclusion: After analyzing several factors that occur concurrently with the genesis of medical error, especially the doctor-patient relationship, the poor working conditions, the scrapping of health in Brazil, the poor quality of medical education, among others to the vulnerability of legal knowledge, as a way of achieving mechanisms that allow them to delineate strategies that minimize the potential risks of unfavorable legal phenomena in the exercise of medical activity. Lastly, as regards the means of proof, it is established that medical expertise is of extreme and indispensable importance for the ample defense of the physician.
\end{abstract}

Key words: Medical Error, Medical Ethics, Malpractice, Imprudence, Neglect, Medical Expertise, Civil Liability.

\section{RESUMEN}

Objetivo: Colaborar para la amplificación de la comprensión de la realidad en busca de seguridad jurídica en el ejercicio de la medicina. Método: Estudio descriptivo, de análisis transversal cualitativo cuantitativo, basado en la evaluación retrospectiva de las Sentencias de los Recursos de Apelación, a través de una investigación de jurisprudencia disponible del Tribunal de Justicia del Estado de Rondônia (TJRO) en el período comprendido entre el 01/01/2015 a 31/04/2018. Resultado: Se analizaron 58 juzgados, teniendo como

${ }^{1}$ Faculdades Integradas Aparício Carvalho (FIMCA), Porto Velho - Rondônia.*E-mail: danielcarlosnetoadv@gmail.com 
principal especialidad en orden decreciente la Obstetricia, Ginecología y Cirugía General. La principal causa petendi fue la negligencia (58,6\%). Se constató que en las causas en las que tuvieron pericia médica el $68 \%$ fueron juzgadas improcedentes y en las que no tuvieron $51,1 \%$ fueron procedentes. Conclusión: Después de análisis, se constataron diversos factores que ocurren concomitantes a la génesis del error médico, sobre todo la relación médico-paciente, las pésimas condiciones de trabajo, la sucateación de la salud en Brasil, la mala calidad de la enseñanza médica, entre otros, frente a la vulnerabilidad de conocimiento jurídico, como forma de alcanzar mecanismos que les permita delinear estrategias que minimicen los riesgos potenciales de fenómenos jurídicos desfavorables en el ejercicio de la actividad médica. Por último, en cuanto a los medios de prueba, se constata que la pericia médica adquiere una importancia extrema e indispensable, para amplia defensa del médico.

Palabras clave: Error Médico, Ética Médica, Impericia, Imprudencia, Negligencia, Pericia Médica, Responsabilidad Civil.

\section{INTRODUÇÃO}

A Responsabilidade Civil Médica tem seu exórdio no Código de Hammurabi (1686-1750 a.C) que impunha penalidades aos médicos que cometessem algum tipo de lesão ou levasse seu paciente ao óbito (GIOSTRI HT, 2011).

Contudo a maior influência para determinação da Responsabilidade do Médico adveio do Direito Francês, com o excepcional parecer do Procurador-Geral André Marie Jean-Jacques Dupin, da Corte Civil do Tribunal de Cassação de Paris, constituindo um marco de extraordinário valor jurídico para o direito francês e alienígena (FRANÇA GV, 2016).

Desde então, o instituto da responsabilidade civil médica vem evoluindo e, atualmente, tem tido transformações desordenadas e complexas na tentativa de acompanhar as necessidades da sociedade, porém, interesses políticos e econômicos não têm respeitado o desenvolvimento regular social, tornando deletéria a aplicação do direito ao caso concreto (NETO DC, 2018).

Tais interesses têm obrigado a população brasileira assistir passivamente um crescimento desordenado no número de faculdades de medicina, contribuindo para um crescimento de $665,8 \%$ de médicos em menos de cinco décadas, contra um aumento populacional de 119,7\% (CREMESP, 2018).

O crescimento de médicos formados em faculdades sem estrutura para treinamento, além de docentes não qualificados, tem coincidido com o aumento no número de erros médicos apreciados pelo Poder Judiciário (NETO DC, 2018).

Segundo informações divulgadas pela Sociedade Brasileira de Direito Médico e Bioética o Superior Tribunal de Justiça registrou entre 2002-2012 um aumento de $1.600 \%$ no número de processos judiciais envolvendo médicos, além de um crescimento de $180 \%$ de profissionais condenados nos tribunais de ética dos Conselhos Regionais de Medicina.

Esses conflitos médico-legais tendem a crescer, pois o sucateamento da saúde pública proporciona condições precárias de trabalho ao médico, além das excessivas jornadas de trabalho que se submetem, refletindo no atendimento ao paciente, ao qual a mudança de paradigma passa a ocupar cada vez mais a posição de consumidor, isto é, menos tolerante com quaisquer espécies de danos (NETO DC, 2018).

Ao mesmo tempo em que se observa a vulnerabilidade dos profissionais médicos, nota-se uma resistência deles na busca pelo conhecimento jurídico como forma de alcançar mecanismos que Ihes permitam delinear estratégias que minimizem os riscos potenciais de fenômenos jurídicos desfavoráveis no exercício da atividade médica (NETO DC, 2018).

Com o propósito de colaborar para a amplificação da compreensão da realidade em busca do máximo de segurança jurídica no exercício da medicina, foi realizado este estudo tendo como objetivo analisar a Jurisprudência do Tribunal de Justiça do Estado de Rondônia, identificando as principais causas, alegações e argumentos dos pacientes ao buscar o Poder Judiciário, além de avaliar quais as especialidades mais demandadas, e qualificar os critérios utilizados pelos juízes na prolação de suas decisões. 


\section{MÉTODOS}

Trata-se de um estudo descritivo, de análise transversal quali-quantitativo, baseado na avaliação retrospectiva dos Acórdãos dos Recursos de Apelação, através de pesquisa de jurisprudência disponível do Tribunal de Justiça do Estado de Rondônia (TJRO) no período compreendido entre 01/01/2015 a 31/04/2018, com o seguinte termo de pesquisa: "erro médico" e "responsabilidade civil por erro médico".Em uma primeira seleção foram encontrados 142 julgados e, posteriomente, após leitura integral dos acórdãos, foram excluídos do estudo as decisões em recursos de agravo de instrumento e embargos de declaração, assim como os acórdãos dos recursos de apelação em que se discutia a responsabilidade de outros profissionais da saúde, demandas por medicamentos, ações extintas por prescrição, decisões que anularam sentença determinando retorno dos autos à primeira instância para nova instrução processual, ações de falha na prestação de serviços de planos de saúde, ações previdenciárias, ações criminais e ações de obrigação de fazer.

Após leitura dos acórdãos, foram selecionados 58 julgados, analisando as seguintes variáveis:Especialidades médicas;Ano de julgamento do recurso;Cidade dos fatos;Se houve realização de perícia;A causa petendi (causa de pedir); Procedência ou Improcedência em primeira instância; Confirmação ou reforma da decisão em segunda instância para os recursos de apelação.Os dados utilizados foram todos da seara pública e disponíveis no endereço eletrônico do Tribunal de Justiça de Rondônia, havendo dispensa do registro e avaliação pelo sistema CEP/CONEP, nos termos do Art. 1ำ, Parágrafoúnico, da Resolução no 510, de 07 de Abril de 2016, não apresentando conflito de interesses. Com o intuito de dar embasamento científico para a discussão, foi realizado levantamento bibliográfico nas bases de dados Pubmed/Medline, Biblioteca Virtual da Saúde, Science Direct e Lilacs, utilizando os descritores Erro Médico/Medical erros/Mala praxis, publicados a partir de 2002, nos idiomas português, inglês e espanhol.

\section{RESULTADOS}

O levantamento online dos julgados resultou em um total de 142 acórdãos; destes, foram analisados e incluídos 58 decisões de interesse para o estudo.Os processos foram divididos por especialidades, observando as seguintes frequências em ordem decrescente: 31\% Obstetrícia, 10,4\% Ginecologia; 10,4\% Cirurgia Geral; 8,6\% Ortopedia; 8,6\% Plantonista de Urgência/Emergência; 8,6\% Clínica Geral; 5,2\% Cirurgia Plástica; 3,5\% Oftalmologia; 3,5\% Imaginologia; 1,7\% Neurologia; 1,7\% Neurocirurgia; $1,7 \%$ Cirurgia Torácica; $1,7 \%$ Pediatria; $1,7 \%$ Mastologia; $1,7 \%$ Cardiologia (Gráfico 1).

Gráfico 1 - Distribuição dos casos de erro médico de ações de responsabilidade civil do TJRO, de acordo com a especialidade.

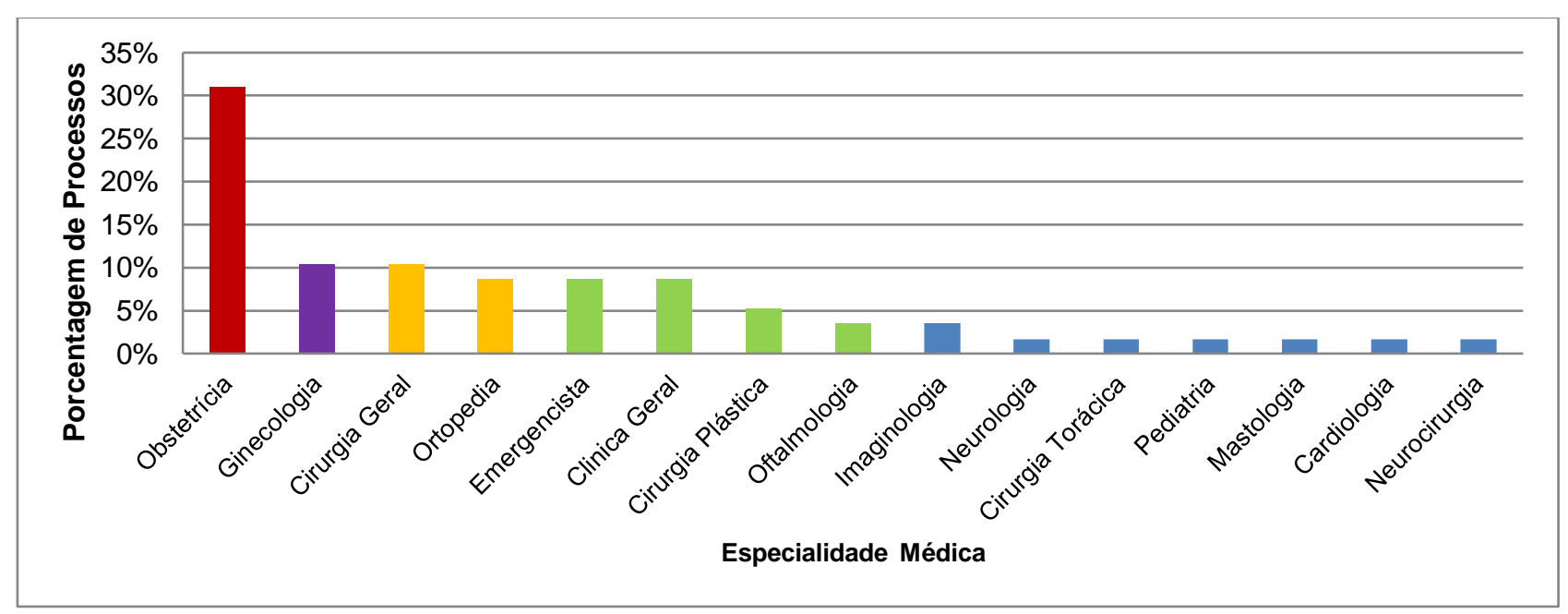

Fonte: Tribunal de Justiça do Estado de Rondônia, 2018. 
Em todas as ações foi analisado a causa petendi (causa de pedir), sendo questionado culpa lato sensu (Negligência, imprudência e imperícia),onde: 58,6\% Negligência; 14\% Imprudência e 3,4\% Imperícia; além de $12 \%$ latrogenia e 12\% Erro de Diagnóstico (Gráfico 2). Nas causas em que se alegava culpa lato sensu $27,6 \%$ resultou em óbito, sendo a maioria na especialidade Obstetrícia.

Gráfico 2 - Distribuição dos tipos de infrações denunciadas.

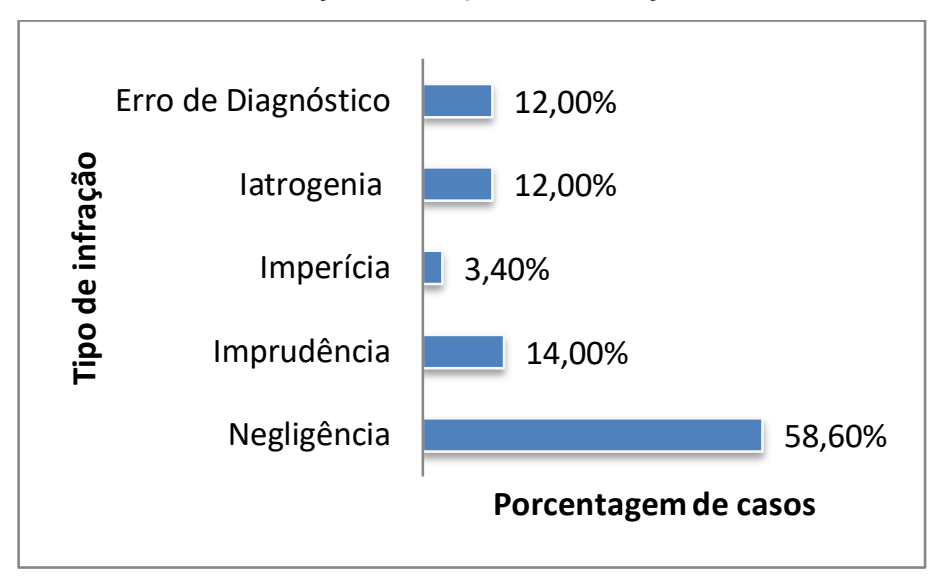

Fonte: Tribunal de Justiça do Estado de Rondônia, 2018.

Em relação à distribuição geográfica, todos os pedidos foram realizados no Estado de Rondônia, e as comarcas de origem foram: 41,4\% Porto Velho; 13,8\% Ariquemes; 10,3\% Ji-Paraná; 7\% Vilhena; 6,9\% Cacoal; 5,2\% Jaru; 3,4\% Colorado; 1,7\% Itapuã; 1,7\% Pimenta Bueno; 1,7\% São Miguel do Guaporé e 1,7\% Rolim de Moura.Em relação à decisão judicial em primeira instância, 36,2\% foram julgadas procedentes e $63,8 \%$ improcedentes, as quais em sede de recurso de apelação para segunda instância no mérito $84,5 \%$ tiveram acórdãos confirmatórios e 15,5\% foram reformadas. Quanto aos meios legítimos de prova, 43,1\% dos casos foi realizado perícia médica e $56,9 \%$ não houve realização de prova pericial. Dos processos que houve perícia médica, $32 \%$ foram julgados procedentes e $68 \%$ improcedentes; dos que não se realizou perícia $51,5 \%$ foram julgados procedentes e 48,5\% improcedentes (Gráfico 3).Em nenhum dos acordos avaliados foi possível ter acesso aos laudos periciais, constando em algumas decisões apenas trechos e conclusões finais dos laudos produzidos.

Gráfico 3 -Análise da importância da Perícia Médica nas sentenças.

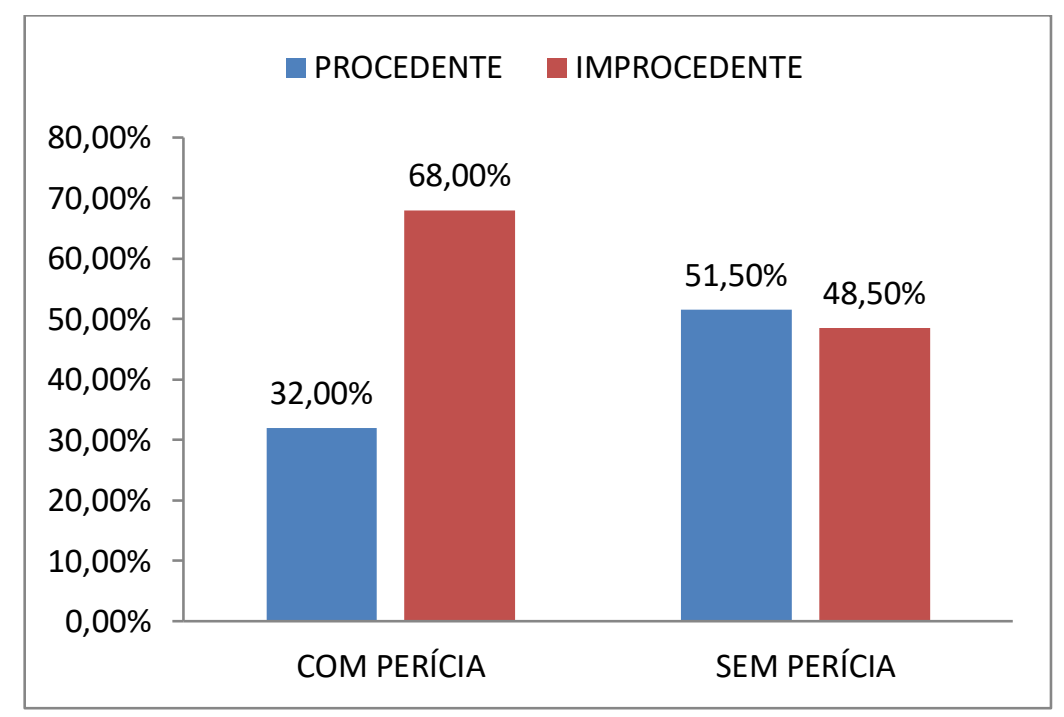

Fonte: Tribunal de Justiça do Estado de Rondônia, 2018. 


\section{DISCUSSÃO}

O Estado de Rondônia foi criado pela Lei n. 41, de 22 de dezembro de 1981, e concomitantemente o Poder Judiciário, instalado no dia 4 de janeiro de 1982, contam atualmente com 23 comarcas. É considerado o terceiro mais populoso e mais rico Estado da Região Norte do Brasil com população aproximada de 1.787.279 habitantes, dividido em 52 municípios, possuindo grande importância no cenário de formação médica, pois alberga quatro faculdades de medicina que ofertam 285 vagas anuais (NETO DC, 2018). Em razão da importância desse Estado à formação médica na região norte, o Tribunal de Rondônia (TJRO) foi eleito para ser analisado no presente trabalho.

Por meio dos resultados encontrados no presente estudo, foi possível revelar a dimensão da atuação profissional médica, em especial pelo alto índice da negligência evidenciada pela falta de cuidado ou precaução com que se executam certos atos, caracterizando-se pela inação, indolência, inércia, passividade, elementos opostos da diligência, do latim diligere, que significa agir com amor, com cuidado e atenção (ROSAS CF, et al., 2004).

Constata-se pelos dados apresentados que $31 \%$ dos erros médicos justificados pela culpa lato sensu, em especial a negligência, são praticados pelos médicos obstetras, com resultado de morte em aproximadamente $27 \%$ dos casos. Todavia a atenção maior deve ser dada a essa especialidade, principalmente pelo fato do presente levantamento ser corroborado pelo estudo realizado em nível nacional no ano de 2017, onde se constatou ser a obstetrícia a especialidade que mais gera processos por erros médicos no Brasil, correspondendo a $23,2 \%$ dos casos (CONJUR, 2017).

Não se pode omitir que o exercício da Medicina, como qualquer outra atividade, não está alheio a infortúnios. Diante dessa adversidade inerente, é preciso questionar não só a quem, como também as condições em que será imputada a respectiva responsabilidade (KFOURI NM, 2018).

Os códigos de ética e a doutrina descrevem que a melhor solução para a dificuldade em atribuir ou não a culpa do médico decorrente de erros, é ter que desvendar se o erro médico foi consequência de uma falha de inexistência de conhecimento científico ou de um erro involuntário, seja de diagnóstico não realizado ou tratamento desconhecido; de outra maneira, se pelo contrário, foi consequência da falta de cumprimento, associado à imperícia, negligência ou imprudência, seja com culpa ou dolo (GIOSTRI HT, 2011).

Outra questão de grande relevância, detectada pelo presente estudo, está na produção de provas que serão avaliadas livremente pelo Juiz, independentemente da parte que a tiver oferecido, podendo formar sua convicção com outras provas carreadas no processo, nos termos do artigo 371 do Novo Código Processo Civil "O juiz apreciará a prova constante dos autos, independentemente do sujeito que a tiver promovido, e indicará na decisão as razões da formação de seu convencimento".A perícia médica é muito utilizada nos processos envolvendo erro médico, pois a demonstração de que o médico atuou com imperícia, imprudência ou negligência, ocasionando dano ao paciente, é uma atividade que suscita grande dificuldade na prática (LOPES JB, 2007).

A prova técnica pericial é importante para o juiz decidir o mérito da sentença nos casos envolvendo erro médico, onde ele precisa determinar se ocorreu culpa provada ou culpa presumida. A perícia ajuda ao magistrado suprir falta de conhecimentos especializados no assunto, já que o juiz é perito somente em matéria de direito e não em matéria médica (NETO DC, 2018).A prova pericial nada mais é que o instrumento destinado a levar ao magistrado elementos sobre fatos que precedem de conhecimentos especiais de ordem técnica (MARQUES JF, 2003)

Assim, a prova pericial é indicada nos casos em que a produção da prova exigir conhecimentos específicos para a sua elaboração. Portanto para a solução da lide, é exigido conhecimento técnico que ambas as partes e o juiz não possuem.A importância desse instrumento de prova é corroborada pelos levantamentos realizados neste estudo, onde nos processos em que se realizou perícia médica, $68 \%$ foram julgados improcedentes, em contrapartida naqueles em que não se realizou a referida análise técnica, $51,5 \%$ foram julgados procedentes (MARINONI LG, et al. 2017). 
Portanto a prova pericial é necessária mesmo que o magistrado possua pessoalmente qualificação para analisar o caso concreto, já que a elucidação do caso não interessa somente ao juiz, pois as partes também possuem direito de discutir o caso e produzir provas segundo o contraditório. Além disso, caso haja recurso, os Desembargadores do Tribunal podem não possuir tal qualificação pessoal, necessitando da prova pericial para decidir o caso (SCAFF FC,2010).

A inquietação no aperfeiçoamento do estudo em relação ao erro médico transcorre do fato de que ultimamente tem-se discorrido sobre o erro médico, mas pouco se sabe sobre sua importância. Partindo de conceitos apriorísticos, observa-se forte convergência em responsabilizar o médico, e apenas o médico, por toda falha ou decorrência adversa do ocorrido na prestação do serviço (NETO DC, 2018).

Com efeito, existe hoje uma série de fatores que colaboram para o acontecimento do erro médico, dentre os quais se destacam a desumanização do atendimento, a mercantilização da medicina, as péssimas condições de trabalho, o tempo reduzido para consulta, entre outros. Como atividade humana, o exercício da medicina depende do efeito cognitivo de aprendizado, concentração, diagnóstico e tomada de decisões, pois está inteiramente afetado por todas as possíveis formas de manifestação do erro (NETO DC, 2018).

Apenas ponderando a real causa, ou todas as causas que colaboraram para a ocorrência do dano, é que poderão ser imputadas as devidas responsabilidades (KFOURI NM, 2018).

Culpar apenas o médico não significa, o mais das vezes, atacar a causa, mas a consequência do problema. Desse modo, é extremamente necessário que haja ação coletiva entre as faculdades de medicina, os conselhos regionais de medicina e os órgãos governamentais de saúde e educação (NETO DC, 2018).

As faculdades devem primar pela formação médica mais humanizada e menos automatizada, dependente da biotecnologia, voltando o aprendizado para a relação médico-paciente, haja vista que nem todos possuem problemas médicos, mas sim "problemas sociais". Portanto essa realidade insofismável da desmedicalização é necessária para se iniciar o processo de "desintoxicação social" (NETO DC, 2017).

Ainda, deve ser incluído na grade curricular dos curso de medicina a disciplina de "Direito Médico" voltada para as nuances da prática profissonal, onde deve-se ensinar instrumentos preventivos, a exemplo do preenchimento juridicamente correto do prontuário médico, a elaboração acurada do consentimento do informado, dentre outras medidas cabíveis e necessárias para gerir potenciais riscos e prevenir futuros prejuízos que lhes poderão ser caros na medida em que houver extensão dos erros (NETO DC, 2018).

Aos Conselhos Regionais de Medicina, cabe sair da inércia político-administrativa e fiscalizar efetivamente a estrutura de funcionamento dos cursos de medicina, tomando providências necessárias ao encerramento daqueles que não têm condições de formar profissionais, além de fornecer constantemente educação médica continuada planejada e eficiente (NETO DC, 2018).

E quanto aos órgãos governamentais, a Saúde deve ser prioridade na agenda política dos governos, e não apenas outdoor nas campanhas eleitorais, o mesmo raciocínio se aplica na autorização desenfreada para abertura de novos cursos de medicina, que deverá ser combatido veementemente, cujos objetivos principais são: os financiamentos de campanha por parte da iniciativa privada e formar mão-de-obra médica barata e especializada, em detrimento de investimentos no setor da saúde e educação (GIOSTRI HT, 2011).

\section{CONCLUSÃO}

Após análise, constatou-se diversos fatores que ocorrem concomitante à gênese do erro médico, sobretudo a relação médico-paciente, as péssimas condições de trabalho, o sucateamento da saúde no Brasil, a má qualidade do ensino médico, entre outros, frente à vulnerabilidade de conhecimento jurídico, como forma de alcançar mecanismos que Ihes permita delinear estratégias que minimizem os riscos potenciais de fenômenos jurídicos desfavoráveis no exercício da atividade médica. Por fim, quanto aos meios de prova, constata-se que a perícia médica assume importância extrema e indispensável, para ampla defesa do médico. 


\section{REFERÊNCIAS}

1. BITENCOURT AG, et al. Análise do erro médico em processos ético-profissionais: implicações na educação médica. Rev. bras. educ. med., Rio de Janeiro, v. 31, n. 3, p. 223-228, dez. 2007.

2. BOYACIYAN K, CAMANO L. O perfil dos médicos denunciados que exercem ginecologia e obstetrícia no estado de São Paulo. Rev. Assoc. Med. Bras., Jun 2006, vol.52, no.3, p.144-147.

3. BRASIL. Consultor Jurídico. Obstetrícia é maior geradora de litígios na medicina, aponta pesquisa. Disponível em: < https://www.conjur.com.br/2017-mai-18/obstetricia-concentra-litigios-medicina-aponta-pesquisa>. Acesso em: 05 mai. 2018

4. BRASIL. Conselho Regional de Medicina do Estado de São Paulo. Demografia Médica 2018. Disponível em: < http://www.cremesp.org.br/?siteAcao=NoticiasC\&id=4941>. Acessoem: 04 mai. 2018.

5. CHAN SB, COHEN D, DORFMAN M. Malpractice claims on emergency physicians: time and money. J Emerg Med. 2012;42(1):22-7.

6. DELDUQUE MC, GOMES TR. O Erro médico sob o olhar do Judiciário: uma investigação no Tribunal de Justiça do Distrito Federal e Territórios. Revista Cadernos Ibero-Americanos de Direito Sanitário. 2017 jan./mar, 6(1):7285.

7. FRANÇA, GV. Direito Médico. 13.ed. Rio de Janeiro: Editora Forense, 2016. P. 254-5.

8. GIOSTRI HT. Erro Médico: à luz da jurisprudência comentada. Curitiba:Juruá, 2011. p.34

9. KFOURI NM. Responsabilidade civil do médico.9. ed. São Paulo: Editora Revista dos Tribunais, 2018.

10. KISS DR, OPITZ JR, SAAD JB, WILIAM A, Erro médico em cirurgia do aparelho digestivo: contribuição para o estudo das provas técnicas, periciais e documentais e suas implicações jurídicas. $A B C D$, arq. bras. cir. dig., Mar 2007, vol.20, no.1, p.23-27.

11. KUMBAR SF, NAYAK RB, RAVEESH BN. Preventing medicallegal issues in clinical practice. Ann Indian Acad Neurol. 2016;19(Suppl 1): S15-20.

12. LOPESJB.A Prova no Direito Processual Civil. 3aㅗ ed. São Paulo: Revista dos Tribunais, 2007, p. 130.

13. MARINONI LG, ARENHART SC, MITIDIERO D. Novo Código de Processo Civil Comentado. 3aㅡ. ed. São Paulo: Revista dos Tribunais, 2017, p. 567 e 569.

14. MARQUESJF. Manual de Direito Processual Civil, vol. 1, 9ª ed., São Paulo: Millennium Editora, 2003.

15. NETO DC. A (Des) Medicalização na Atenção Primária: o surgimento de um novo cenário Na Saúde Pública. Revista Científica Fagoc Saúde, v. 1, p. 09-14, 2017

16. NETO DC. Direito Médico à luz da doutrina e jurisprudência: para médicos e residentes. $2^{a}$ ed - Revista e Ampliada. Porto Velho: Motres, 2018.

17. PORRAS JS. El seguro contra laresponsabilidad civil del médico. Med. leg. Costa Rica, Set 1999, vol.16, no.1-2, p.21-27.

18. RENGIFO CA, et al. Responsablidadetica y legal enlareferência médica, de pacientes trasladados al Servicio de Toxicologíadel Hospital de Coche. RFM, Ene 2004, vol.27, no.1, p.69-73.

19. ROSAS CF, et al. Ética em ginecologia e obstetrícia. 3a ed. São Paulo: Conselho Regional de Medicina do Estado de São Paulo, 2004.

20. SCAFF FC. Direito à saúde no direito privado. 1a ed. São Paulo: Saraiva, 2010. p. 106 e SS.

21. UDELSMANN A. Responsabilidade civil, penal e ética dos médicos. Rev Assoc Med Bras. 2002;48(2):172-82.

22. YAMAUTI K, ZERBINI T. A oftalmologia no tribunal: avaliação das sentenças judiciais no âmbito do Tribunal de Justiça do Estado de São Paulo. Saúde, Ética \& Justiça, v. 19, n. 2, p. 78-85, 5 dez. 2014. 